\title{
Effective Designing of Order Picking Systems Using Dynamic Simulation
}

\author{
Petra Kašparová (D), Jakub Dyntar \\ Faculty of Economics, Technical University of Liberec, Voroněžská 13, 46001 Liberec, Czech Republic \\ Corresponding author: Petra Kašparová (petra.kasparova1@tul.cz)
}

\begin{abstract}
In this article, we describe the use of dynamic simulation when designing an effective system for order picking within a distribution warehouse. The simulation model was created in the Witness software environment for discrete dynamic simulation and is a modification of a general simulation model of material flows in supplier systems. Using the example of a batch system for picking orders in a drugstore goods warehouse, we discuss the possibilities of using a general simulation model of material flows as an effective framework for the development of system support for warehouse processes using WMS. The simulation model is based on the possibility of dividing any material flow in the supply system into a finite number of movements with the possibility of using one of the sources and fulfilment of certain conditions. In order to achieve the required optimisation of the order picking system, which depends, in particular, on the unknown duration of goods collection at the picking location, and on the duration of goods sorting in consolidation, the "what-if" analysis has been used as a tool to measure the impact of uncertainty of one or more variables entering the model on the uncertainty of output variables. The study showed that minimisation of the number of physical elements in the model leads to a significantly higher speed of its operation. By means of dynamic simulation, it is possible to test a large number of variants of the picking system layout in a relatively short time and minimise the risk of erroneous decisions associated with the implementation of a suitable WMS.
\end{abstract}

\section{Keywords}

Picking of orders, Controlled warehouse, Warehouse management system, Dynamic simulation, Logistics. 


\section{Introduction}

In terms of operating costs, the process of picking customer orders is the most important activity that takes place in distribution warehouses (Tompkins et al., 2010). The picking is very laborious, forming up to $55 \%$ of the costs associated with the warehouse operation, and up to $50 \%$ of the picking time is consumed by the movement of operators to reach goods localised at picking positions (de Koster et al., 2007). Due to the fact that customer behaviour is characterised by constant pressure aimed at reducing the order processing time and by purchasing smaller quantities more frequently, good work organisation is crucial for the efficiency of order picking in the warehouse (M. Yu \& de Koster, 2009).

Designing picking systems, including system support, is one of the most difficult roles of logistics planning due to its considerable complexity (Altarazi \& Ammouri, 2018). The system performance is influenced, for example, by the availability of resources such as premises, warehouse racking and handling equipment or availability of labour force (Gu et al., 2007). Effective system support of order picking is ensured by application of the controlled storage principles (i.e., the Warehouse Management System - WMS). This system provides information enabling control of the product or goods flow from receipt to dispatch thereof. They then become the basis for the proper operation of other business departments, such as purchase and sales. The WMS must be connected and able to communicate with other information systems across the company (Faber et al., 2002). WMS system integration provides companies with a competitive advantage in responding effectively to changes in internal or customer requirements or to those coming from the market.

The key factors of optimal controlled storage functioning include, in particular (Bottani et al., 2019):

- the warehouse layout;

- the picking system type;

- the order picking strategy;

- the storage assignment policy; and

- the routing of workers responsible for order picking between the individual locations.

The warehouse layout is either conventional, i.e., with rectangular arrangement and parallel aisles, or non-conventional (Çelk \& Süral, 2014). The non-conventional warehouse layout usually has a "fishbone" or "flying V" form, and is used, for example, for a low number of items in the order (Gue \& Meller, 2009).

The picking system type is either static, where the worker moves around goods that are firmly located, or dynamic, where the goods are moved to the picking point according to the worker's requirements and returned to the warehouse after the required quantity has been removed (Lahmar, 2007). As regards static picking systems, which are most common in practice, we can distinguish between picking on the ground, i.e., within the reach of the worker who is standing on the ground (Dallari et al., 2009), and picking at height using special handling equipment (Pan et al., 2014).

The strategies of order picking include individual, zone and batch picking (Ho \& Lin, 2017). Individual picking means that the worker picks only one order at a time in its entirety. What is typical of zone picking is assignment of a worker to a certain fixed part of the warehouse (zone), where they pick parts of orders. During the sequence zone picking, they then pass a partially picked order to the next zone, while in the case of synchronised zone picking, the individual parts of orders are picked simultaneously in all zones and then usually consolidated via the sorting system (Bottani et al., 2019). Combining orders and picking them at the same time is typical of batch picking. The advantage of this method of collective order picking is significant saving of the time spent on the movement of operators to reach goods located at picking positions; nevertheless, there is a disadvantage consisting in the need to implement a related process of sorting goods into individual customer orders (Parikh \& Meller, 2008). 
The simplest methods of ordering goods at picking positions include random placement of the item into the assigned empty place (Fukunari \& Malmborg, 2008) or maintenance of assortment groups in certain fixed zones (Petersen \& Aase, 2004). The disadvantage of random placement of the item into an empty place is consumption of more time when workers move between picking locations, and the disadvantage of keeping the assortment groups is then poor utilisation of the warehouse space (Sooksaksun, 2012). Therefore, what is more often used in practice is the ordering of goods based on classes that are defined using certain criteria determined in advance (Önüt et al., 2008). Such criteria usually concern the share in the turnover or the frequency of goods occurrence in orders for a certain period (Y. Yu et al., 2015), where goods are sorted by means of the ABC analysis into 3 classes (Shah, 2009) and each class is assigned a certain part of the warehouse within which the goods are randomly placed to particular picking positions (Li et al., 2018).

Finally, the route between the individual locations, along which the employee responsible for picking the order moves, can be proposed using a number of methods. Most often it is the S-method, the return method and the biggest gap method (Cano et al., 2017).

If we combine the options described above for each factor influencing the picking system efficiency, we will receive a large number of different configuration variants, each of which may theoretically be the most suitable for a particular distribution channel with a specific order composition and service level requirement, while at the same time leading to minimum warehouse operating costs. Bottani et al. (2019) refer to dynamic simulation as to a suitable method to determine the effectiveness of a specific picking system layout. Simulation is a process of creating a logical-mathematical model of a real object, a system defined on it or a decision-making process and implementation of a large number of experiments with it, the purpose of which is to describe the system, recognise its function and estimate its future behaviour (Gros \& Dyntar, 2015). The advantage of simulation is the possibility to verify a large number of variants of system layout before resources are spent on the actual implementation (Law, 2013). Although simulation is widely used as a method to address various problems in the design of distribution warehouses, there are only a limited number of studies in the literature on designing framework models suitable for verifying the effectiveness of picking system layouts.

The purpose of this article is to describe the use of dynamic simulations in the design of an effective system of order picking in a drugstore goods warehouse. The simulation model of the system was created in the Witness software environment for discrete dynamic simulation with MS Excel support for the import of input data and the export and modification of outputs, and is based on a general simulation model of material flows in supplier systems (Dyntar, 2018).

This is based on the assumption that any material flow in the supplier system can be broken down into a final number of movements, and the execution of a movement may require the use of any source and the fulfilment of any conditions. Based on the model outputs, we discuss the possibilities of using the general simulation model of material flows as a framework for development and system support of warehouse processes using the WMS. The Witness simulation software is widely used to manage and optimise production and logistics systems, and it can be applied successfully as support to supply chain modelling and optimisation, or it can simulate business processes effectively (Wang et al., 2020).

The outputs obtained were further verified by the what-if analysis. The what-if analysis measures how uncertainty of one or more variables entering the model may affect the uncertainty of the output variables (Baio \& Dawid, 2015). The most common forms include the what-if analysis of one variable, the multiple analysis and the probability analysis (Pichery, 2014). 


\section{Methods and input data}

The general simulation model, the modelled system and simulated scenarios are briefly described in this chapter.

\subsection{Modelled system}

The modelled system is a drugstore goods warehouse that supplies a network of 230 retail outlets in Slovakia. Based on the ABC analysis of sales data for $2019,80 \%$ of the turnover was found to comprise 1,449 items (i.e., group A), a further $15 \%$ of the turnover consisted of 1,736 items (i.e., group B) and the remaining $5 \%$ of 3,439 items (group $C$ ). The outlets' demand is rather stable throughout the year in terms of the number of orders and items per order and shows a slight pre-Christmas season (see Figure 1). The median of the number of items per order is 109. The outlets are supplied from the warehouse on the basis of a distribution plan regularly twice a week.

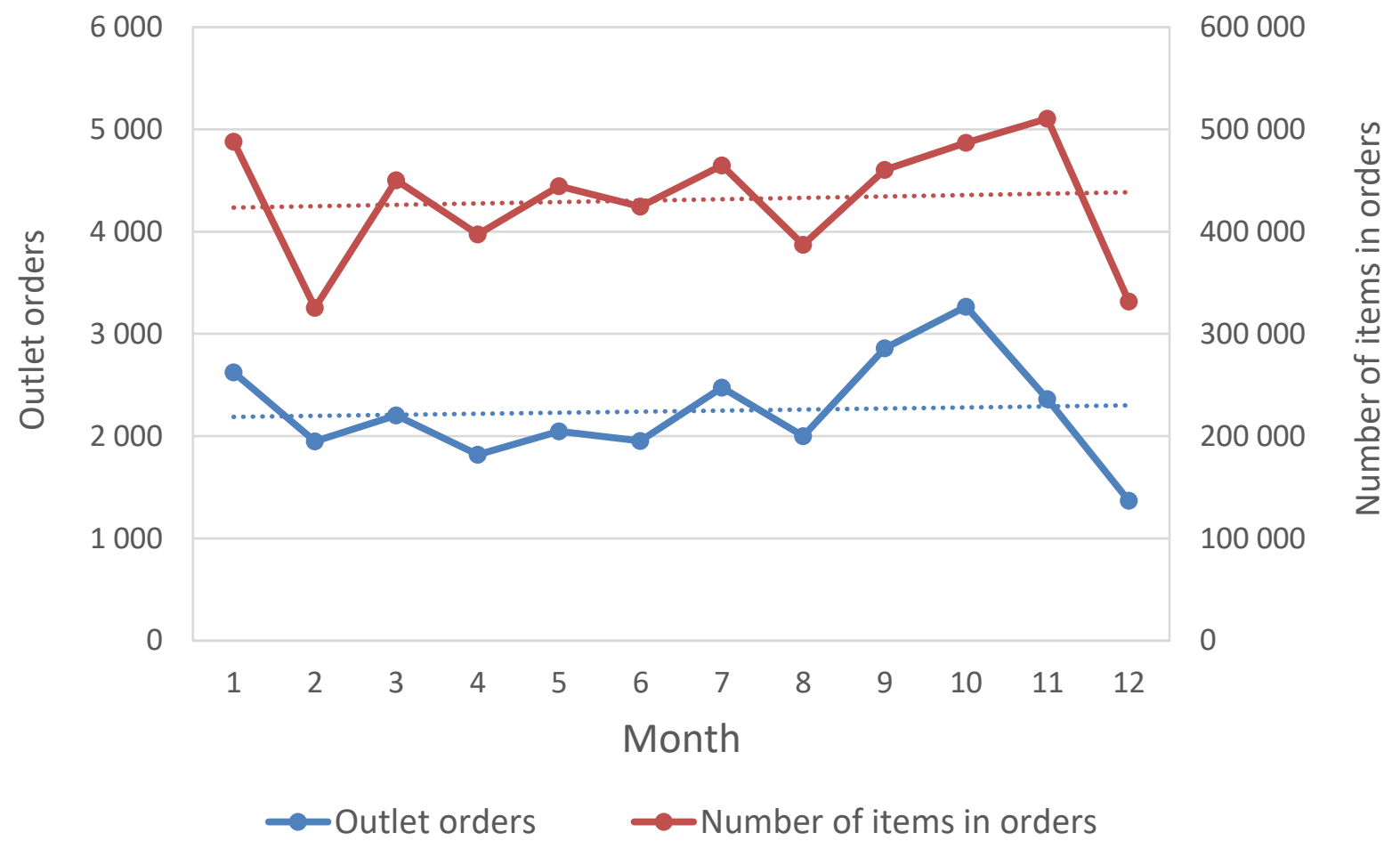

Figure 1: Number of orders and items in orders. 
The warehouse layout is shown in Figure 2.

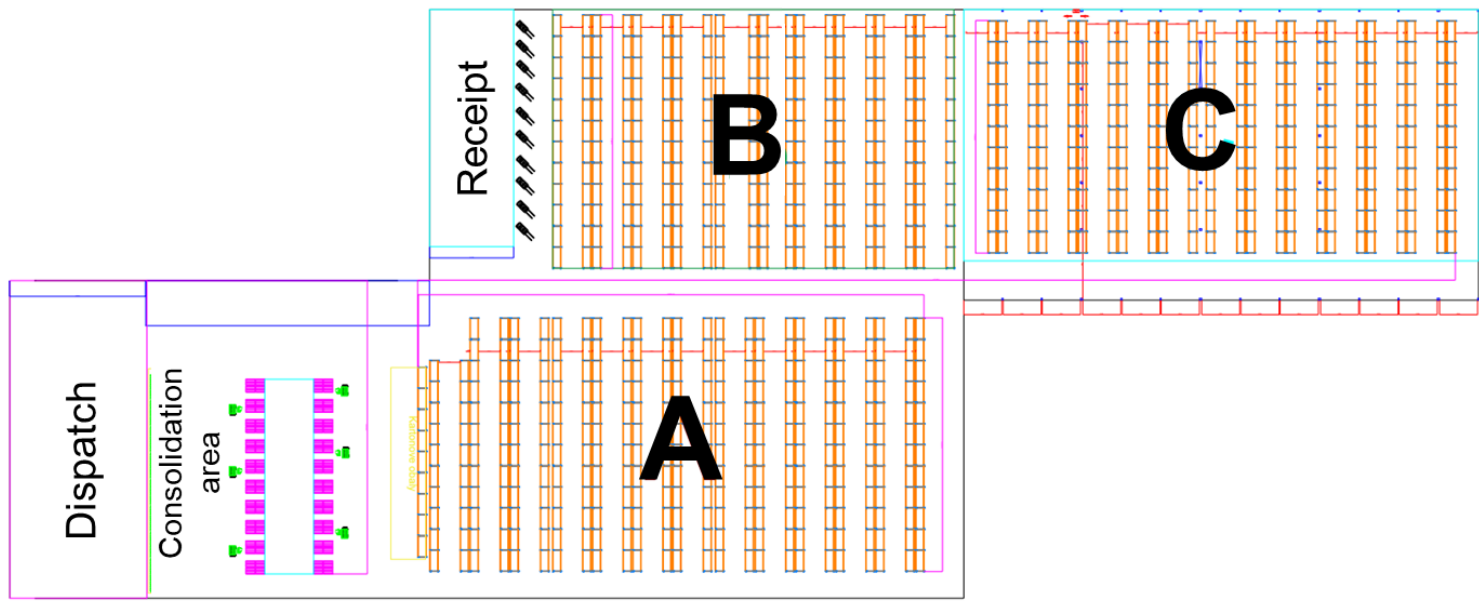

Figure 2: Warehouse layout.

The warehouse capacity is 10,430 pallets, and the number of picking positions has increased to 5,215 as compared to the original state thanks to the introduction of picking trolleys allowing picking at a height of ground+2. The introduction of new picking trolleys with a load capacity of $400 \mathrm{~kg}$ is also associated with a significant increase in the expected average speed of movement of the worker performing the order picking (hereinafter referred to as picker) from $3 \mathrm{~km} / \mathrm{h}$ (original condition, walking) to $6 \mathrm{~km} / \mathrm{h}$. While assortment groups in certain fixed zones were maintained in the original picking system, the modelled system includes random placement of goods in zones A, B, C based on their share in the turnover. The movement of the warehouseman along the route obtained by the S-method is considered in zone $\mathrm{A}$, while zones $B$ and $C$ use the return method. The last change considered in the modelled system is the transition from individual picking to batch picking. This means that orders placed by outlets are combined, within one day, into an internal order containing all the demanded items and the total demanded quantity thereof. The individual parts of the internal order are then assigned to pickers for picking so that the maximum permissible quantity of goods on the pallet (i.e., the load capacity of the picking trolley) is not exceeded. After picking a part of the internal order, this part is taken to the consolidation area, where the goods are sorted according to the orders from the outlets.

\subsection{General simulation model of material flows}

The system model is created in the Witness environment in the structure of the general simulation model of material flows (see Dyntar, 2018, page 84-118). In the general simulation model of material flows logic, each flow can be broken down into a finite number of movements. Each movement consists of four mutually related actions, which are simulated by the Part type element passing through the basic model structure (BMS), which consists of four Machine type elements. Part and Machine type elements are available in the Witness environment in a predefined form. In the BMS, two Machine type elements represent handling of the entity without changing its position, and two elements represent a change of the entity position. The specific material flow and its logic in the model are created in the Actions elements of the Machine type that make up the BMS using the program code and by making the input and output rules conditional.

In the modelled system described in Chapter 2.1, the movements of picking of a part of the internal order and consolidation of outlet orders are simulated. While the consolidation of orders from outlets is modelled using the BMS described above, the BMS is modified to model the order picking. Such modification consists in the repeated transfer of the Part pKulicka type element between the Machine type elements forming a BMS mManipulaceBod1 and mPohybBod1Bod2 (see Figure 3). 
Part of the internal order is not completed

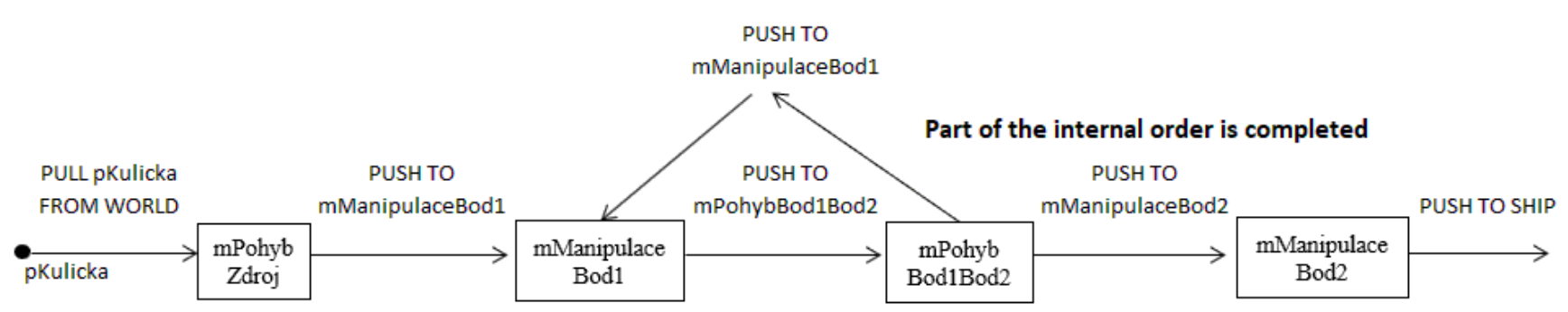

Figure 3: BMS modification for simulation of picking of a part of an internal order.

This corresponds to a situation where during the picking of a part of the internal order the picker moves repeatedly along the shortest route between two subsequent picking locations with goods (dynamic change of points 1 and 2 in the BMS) until the picking is over, and they then move to the consolidation area. The BMS modification referred to above is carried out by adjusting the program code of the Output Rule element mPohybBod1Bod2, where the output rule is conditioned by the logical structure of IF/ELSE/ENDIF. The requirements for executing a picking movement of part of an internal order are imported into the simulation from MS Excel and coded into the Variable type element. Each line of this element represents picking of one item, the columns contain information about what part of the internal order and what item is concerned, in what quantity the item is to be selected for the picking location and where the picking location is situated in the warehouse.

The order of picking locations entering the simulation ensures the picker's movement along the shortest route without having to return and is in accordance with the selected movement methods for groups A, B, C. In order to avoid slowing down the simulation run, random generation of picking locations and the sequencing thereof is already carried out in MS Excel. Random generation of picking locations is done using the RANDBETWEEN() function, ordering using Order/Upwardly according to the picking location number, where the A group items are situated in locations 1-156 in the respective part of the warehouse according to the layout (see Figure 2), the B group items in locations 157-276 and the C group items in locations 277-419. The shortest distances between the picking locations are obtained in MS Excel by means of dynamic programming, arranged in a square matrix $(\mathrm{m}=419)$, imported into the simulation and coded into the Variable type element. The assignment of a certain number of items in a certain quantity to the part of the internal order which is assigned to pickers in the simulation is again done in MS Excel using macros, taking into account the maximum quantity of goods on the pallet. First, parts of the internal order are created, where the subject of picking is only one item in the quantity corresponding to the limit, then the parts of the internal order with more than one item are followed. After completing the simulation of the movement of the part of the internal order, the requirements for the implementation of the outlet order consolidation movement are coded into the Variable type element so that the Variable type element is increased by the number of items that arrived in the consolidation after the picking and become the subject of sorting. The required output of the simulation is the minimum daily number of BMS, which is necessary for the execution of movements corresponding to outlet orders in 2019 during the considered one-shift operation, the available time of 7.5 hours/BMS, the shift and the division of worker groups into pickers and consolidators without mutual penetration.

\subsection{Simulated scenarios}

The basic assumption that especially the duration of goods collection at the picking location and the duration of the goods sorting in consolidation, which are not known in advance, affect the required simulation outputs was verified using the what-if analysis. Please note that a change of the maximum of one variable is considered in all the simulated scenarios included in this study. 
First of all, we simulated a scenario in which we looked into the influence of a change in the average duration of the collection of goods at the picking location on the need for pickers (see Table 1).

Table 1: Input parameters of the simulation - Scenario 1.

\begin{tabular}{|lcc|}
\hline Average duration of collection of goods at picking location & $10-120$ step 5 & [s/item] \\
\hline Maximum quantity of goods on pallet & 400 & $\mathrm{~kg}$ \\
\hline
\end{tabular}

In the first stage, we identified the minimum daily need for pickers for each day for the period of October, which is one of the busiest months in terms of the volume of goods ordered by outlets, and selected the maximum value out of them. In the second stage, we simulated the entire period by days for the required maximum number of pickers, which is linked to a certain duration of the collection of goods at the picking location in order to verify that the requirement is met. The required maximum number of pickers is 14 and is based on the specified return on investment in picking trolleys and system support using WMS, which includes the assumption of saving the warehouse operating costs by reducing the number of picking workers compared to the original condition.

Afterwards, we simulated the scenario in which we examined the impact of the maximum quantity of goods on the pallet during picking on the need for pickers (see Table 2).

Table 2: Input parameters of the simulation - Scenario 2.

\begin{tabular}{lccc}
\hline Average duration of collection of goods at picking location & 70 & [s/item] \\
\hline Maximum quantity of goods on pallet & $100-400$ step 50 & $\mathrm{~kg}$
\end{tabular}

The simulated period was October 2019, and the average duration of goods picking at the picking location corresponded to the Scenario 1 simulation output for the maximum required number of pickers.

Finally, in the last simulated scenario, we looked into the sensitivity of the need for consolidators to a change in the average duration of goods sorting in consolidation (see Table 3), with the maximum quantity of goods on a pallet corresponding to the loading capacity of the picking trolley and with the average duration of the goods collection at the picking location corresponding to the Scenario 1 simulation output for the maximum required number of pickers.

Table 3: Input parameters of the simulation - Scenario 3.

\begin{tabular}{lccc}
\hline Average duration of collection of goods at picking location & 70 & [s/item] \\
\hline Maximum quantity of goods on pallet & 400 & $\mathrm{~kg}$ \\
\hline Average duration of sorting of goods in consolidation & $10-60$ step 1 & [s/item] \\
\hline
\end{tabular}

Like with Scenario 1, we identified the minimum daily need for consolidators in the first stage for each day of October and selected the maximum value out of them. In the second stage, we simulated the period of the entire year by days for the required maximum number of consolidators, which is linked to a certain 
duration of sorting of goods in consolidation to verify that the requirement was met. The required maximum number of consolidators is 4 .

The simulation model was created in the Witness 14 environment with the support of MS Excel 2016 for import of inputs. The scenario simulations were performed on a computer with an Intel Core i7 $7600 \mathrm{U}$ $-2.9 \mathrm{GHz}$ processor, 16 GB RAM.

\section{Results}

The simulation results show that in order to comply with the requirement for the maximum number of pickers (i.e., 14), the average time of the goods collection at the picking location must not exceed $70 \mathrm{~s} /$ item (see Figure 4). This was also confirmed by simulation of the entire period (see Figure 5). When the average duration of the goods collection at the picking location changes by 5 seconds/item, the need for pickers changes by 1 (see Figure 4).

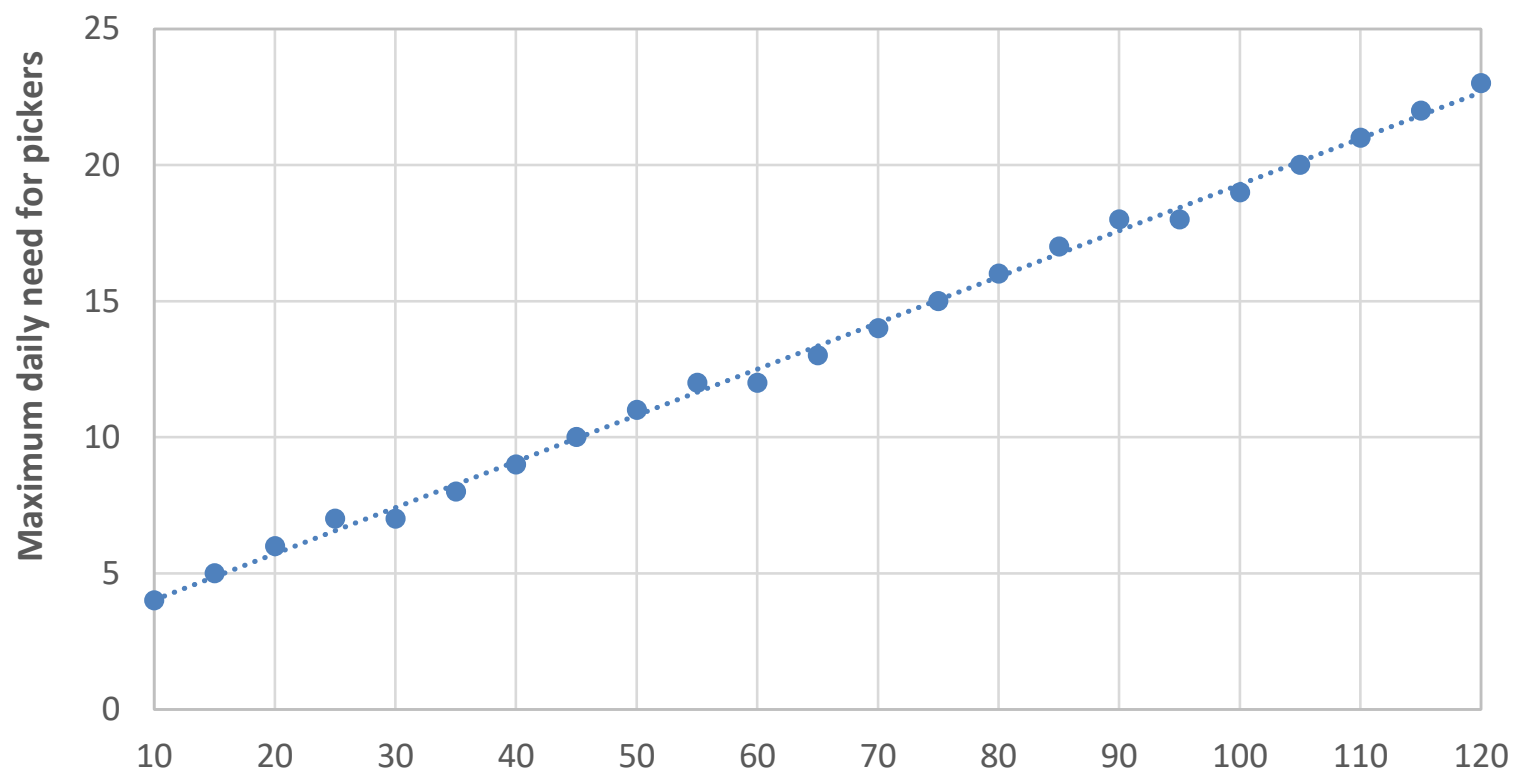

Average duration of the goods collection at the picking location [sec/item]

Figure 4: Need for pickers depending on average duration of goods collection per picking location. 


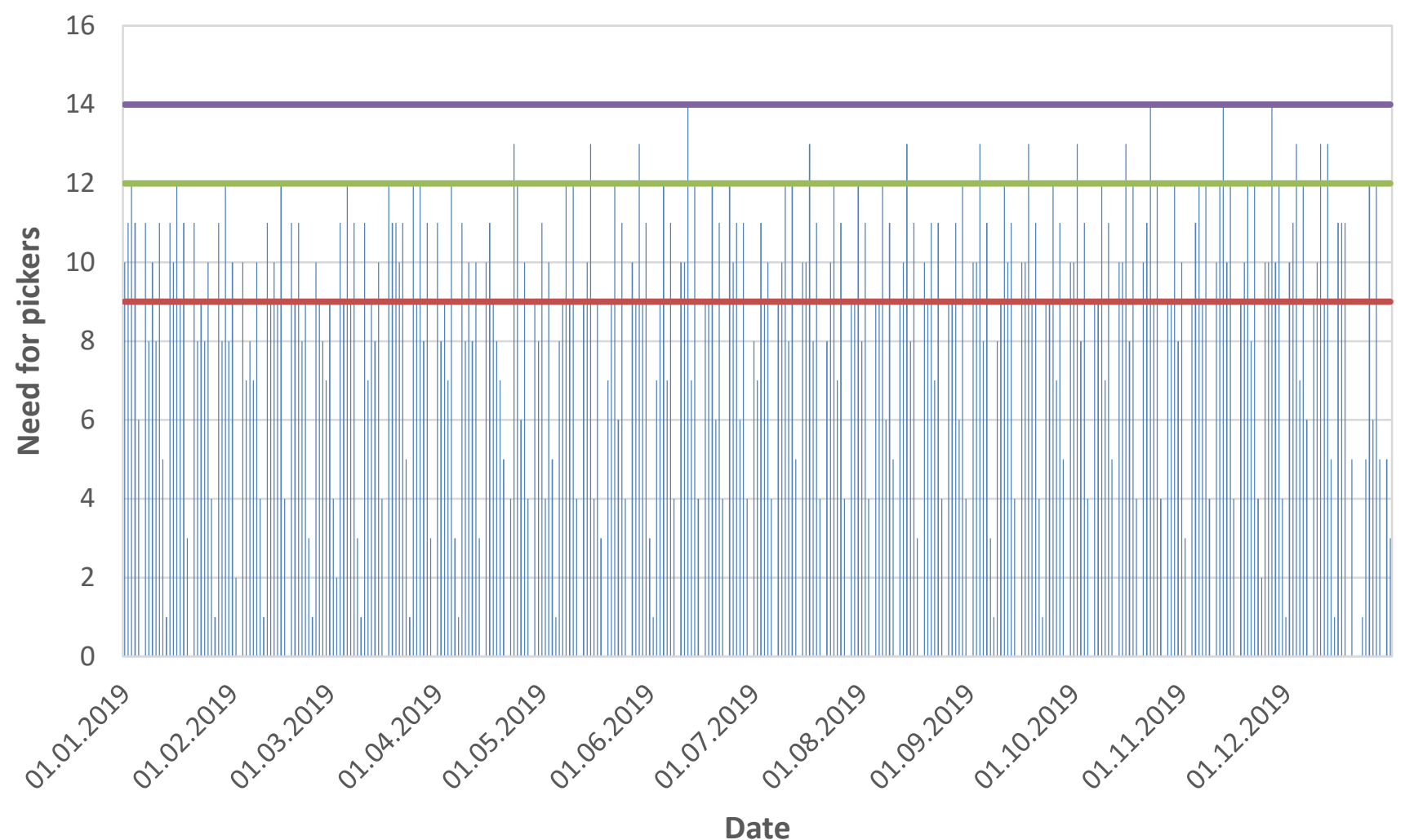

Need for pickers -Median $\longrightarrow$ Quantile 95\% $\longrightarrow$ Maximum

Figure 5: Need for pickers throughout the year.

The simulation results further show that if it is not possible to use the maximum load capacity of the picking trolley due, for example, to excessive volume or instability of the handling unit, the need for pickers will first increase slightly (i.e., by 1 picker within the range of 250-400 kg of goods per pallet), and this increase accelerates in the event of further decrease in the capacity utilisation (see Figure 6).

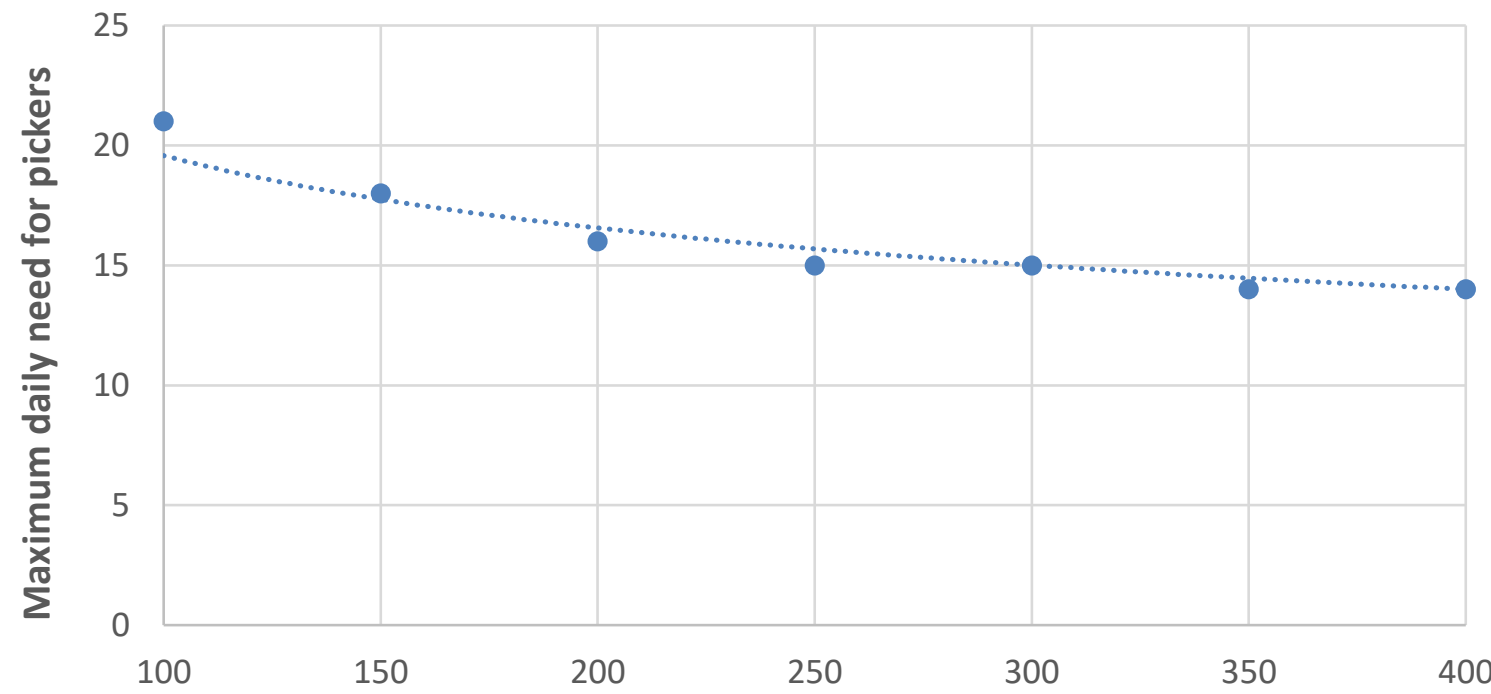

Maximum quantity of goods per pallet [kg]

Figure 6: Need for pickers depending on maximum quantity of goods on pallet. 
Finally, the simulation outputs show that in the case of a requirement for the maximum number of consolidators (i.e., 4), the average time of sorting goods in consolidation must not exceed $25 \mathrm{~s} /$ item (see Figure 7). As for the need for consolidators, there is an increase by 1 upon a change in the average duration of the goods sorting in consolidation by $6-7 \mathrm{~s} / \mathrm{item}$.

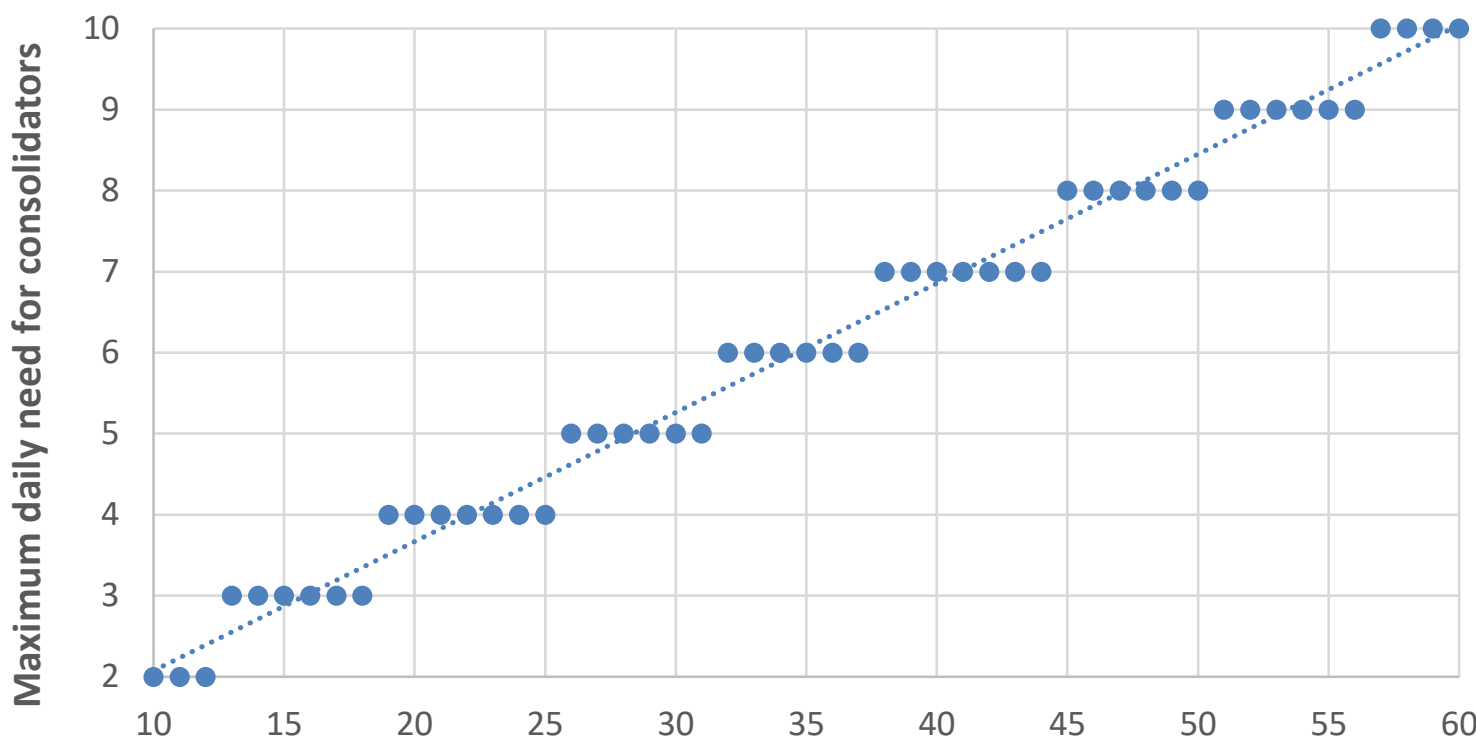

Average duration of sorting of goods in consolidation [sec/item]

Figure: 7: Need for consolidators depending on average duration of sorting of goods in consolidation.

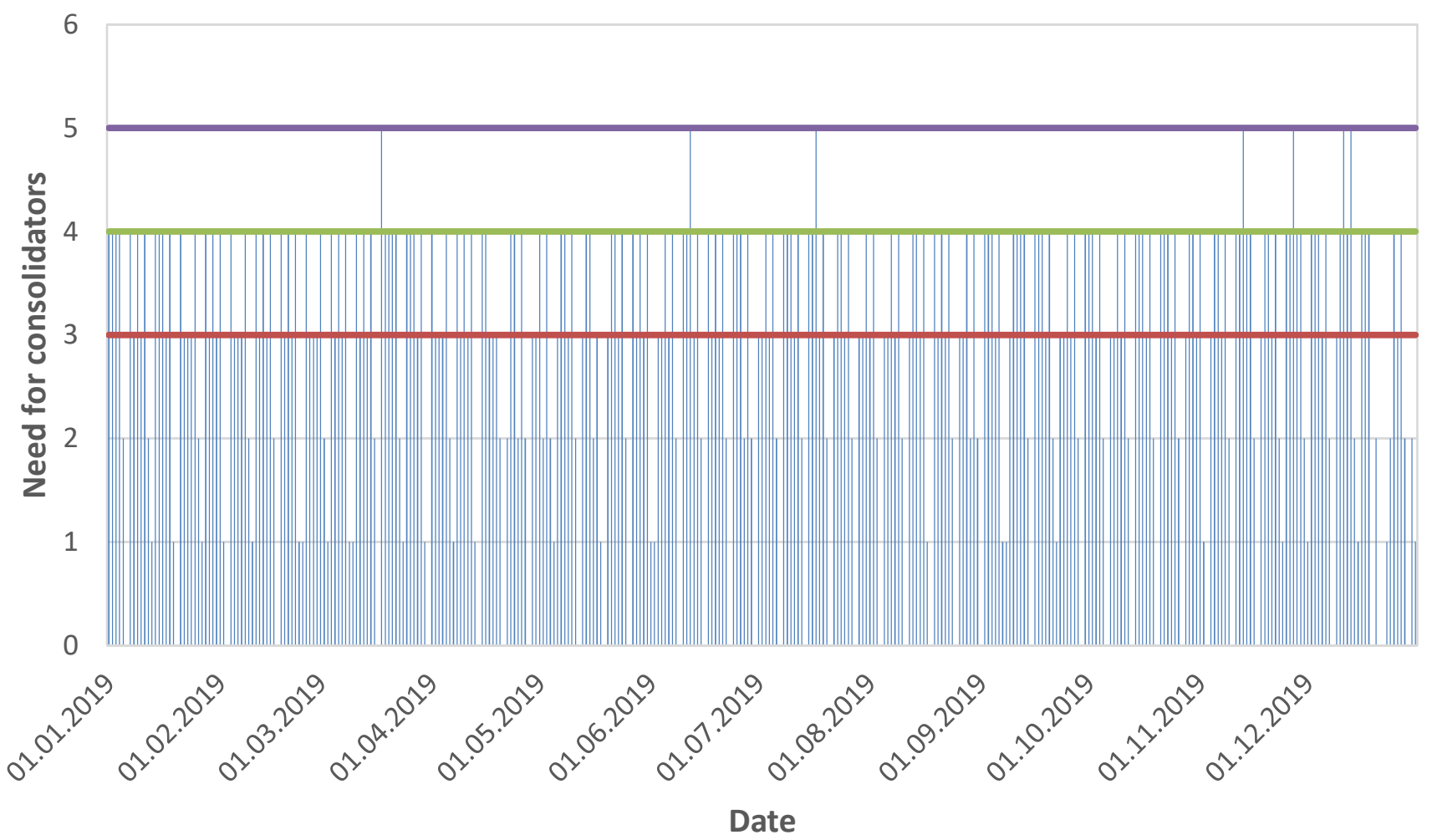

Need for consolidators -Median $\longrightarrow$ Quantile 95\% Maximum

Figure 8: Need for consolidators throughout the year. 
We point out that during the simulation of the entire period, with the stated average time of goods sorting in consolidation of $25 \mathrm{~s} /$ item, the need for the consolidators in 7 days reached the limit of 5 (see Figure 8), which was found to be negligible by the company operating the warehouse.

Potential faster or slower picking and consolidation associated with the increase or decrease in the need for workers has a direct impact on the return on investment in picking trolleys and system support of these processes through the WMS.

\section{Discussion and conclusion}

A very frequent method used to solve problems associated with optimising the order picking process is mathematical programming (e.g., Bolaños Zuñiga et al., 2020; Cano et al., 2020; Scholz et al., 2016). The presented models are similarly focused on improving the efficiency of order picking, allocation of storage places and inclusion of significant restrictions resulting from the basic characteristics of individual case studies (Bolaños Zuñiga et al., 2020). Dynamic simulation is an alternative to the design and optimisation of the logistics system through mathematical programming.

Many studies demonstrate the effectiveness of dynamic simulation as a tool of strategic support in the design of very complex logistics systems (Helo, 2000; Manzini et al., 2005, 2007; Riddalls et al., 2000). The result of the proposals thereof is an integrated approach which, at the same time, applies different decision-making techniques based on both analytical and dynamic multi-parametric models. However, studies in scientific literature that use dynamic simulation often lack the detail of the model, and there is a high degree of dependence on the selected software, where each manufacturer offers different element logic and complexity.

The environment of the dynamic simulation and the chosen modelling technique bring a number of advantages in terms of design of picking systems and their system support through WMS. Minimising the number of physical elements such as Part, Buffer and Machine in the model leads to a significantly higher speed of its operation. The simulation of one year in the modelled system, which is the subject of this study, lasted 72 seconds using the above-mentioned computer technology configuration. This means that it is possible to test a large number of variants of the picking system layout in a relatively short time and decide on the most appropriate method of system support before the WMS implementation itself. It is also possible to use the simulation as a powerful tool to support resource planning for the expected mix of orders in a shorter period. This is beneficial, for example, in the months that make up the high season.

By adding new movements to the simulation, the modelled system can be expanded by the material flows implemented in other warehouse processes, thus achieving the effects resulting from the integration thereof in the entire logistic system. The BMS in the form described in Dyntar (2018) can be used to simulate processes running upon receipt in the warehouse (e.g., unloading of goods, checking of completeness and quality of delivery, etc.) and also to simulate controlled storage of homogeneous handling units with goods after the receipt or processes taking place in dispatch (e.g., check of the order completeness, packaging, loading, etc.). The modified BMS, which is described in Chapter 2.2, can be used to simulate controlled storage of heterogeneous handling units with goods after the receipt or storage of sorted returned goods as part of the implementation of return flows. Thanks to its simplicity and use of a limited range of physical elements, the model can be easily transferred into the environments of other simulation products such as Simul8 or Arena. As the present case study deals with supplies under the B2B scheme, possible fluctuations in the behaviour of orders during the day are not taken into account. Further research can therefore focus on adjusting the model for e-commerce, where there is a much higher risk of dynamic stock behaviour during the day. 


\section{Additional Information and Declarations}

Conflict of Interests: The authors declare no conflict of interest.

Author Contributions: P.K.: Methodology, Conceptualization, Writing - Original draft preparation, Writing - Reviewing and Editing. J.D.: Data curation, Software, Writing Original draft preparation, Supervision.

Data Availability: The data that support the findings of this study are available from the corresponding author.

\section{References}

Altarazi, S. A., \& Ammouri, M. M. (2018). Concurrent manual-order-picking warehouse design: A simulation-based design of experiments approach. International Journal of Production Research, 56(23), 7103-7121. https://doi.org/10.1080/00207543.2017.1421780

Baio, G., \& Dawid, A. P. (2015). Probabilistic sensitivity analysis in health economics. Statistical Methods in Medical Research, 24(6), 615-634. https://doi.org/10.1177/0962280211419832

Bolaños Zuñiga, J., Saucedo Martínez, J. A., Salais Fierro, T. E., \& Marmolejo Saucedo, J. A. (2020). Optimization of the Storage Location Assignment and the Picker-Routing Problem by Using Mathematical Programming. Applied Sciences, 10(2), no. 534. https://doi.org/10.3390/app10020534

Bottani, E., Volpi, A., \& Montanari, R. (2019). Design and optimization of order picking systems: An integrated procedure and two case studies. Computers \& Industrial Engineering, 137, no. 106035. https://doi.org/10.1016/j.cie.2019.106035

Cano, J. A., Correa-Espinal, A. A., \& Gómez-Montoya, R. A. (2017). An Evaluation of Picking Routing Policies to Improve Warehouse Efficiency. International Journal of Industrial Engineering and Management, 8(4), 229-238.

Cano, J. A., Correa-Espinal, A. A., \& Gómez-Montoya, R. A. (2020). Mathematical programming modeling for joint order batching, sequencing and picker routing problems in manual order picking systems. Journal of King Saud University Engineering Sciences, 32(3), 219-228. https://doi.org/10.1016/j.jksues.2019.02.004

Çelk, M., \& Süral, H. (2014). Order picking under random and turnover-based storage policies in fishbone aisle warehouses. IIE Transactions, 46(3), 283-300. https://doi.org/10.1080/0740817X.2013.768871

Dallari, F., Marchet, G., \& Melacini, M. (2009). Design of order picking system. The International Journal of Advanced Manufacturing Technology, 42(1-2), 1-12. https://doi.org/10.1007/s00170-008-1571-9

de Koster, R., Le-Duc, T., \& Roodbergen, K. J. (2007). Design and control of warehouse order picking: A literature review. European Journal of Operational Research, 182(2), 481-501. https://doi.org/10.1016/j.ejor.2006.07.009

Dyntar, J. (2018). Návrh a optimalizace dodavatelských systémů s využitím dynamické simulace. FinEco.

Faber, N., De Koster, R., \& Van De Velde, S. (2002). Linking warehouse complexity to warehouse planning and control structure: An exploratory study of the use of warehouse management information systems. International Journal of Physical Distribution \& Logistics Management, 32, 381-395. https://doi.org/10.1108/09600030210434161

Fukunari, M., \& Malmborg, C. J. (2008). A heuristic travel time model for random storage systems using closest open location load dispatching. International Journal of Production Research, 46(8), 2215-2228. https://doi.org/10.1080/00207540601118462

Gros, I., \& Dyntar, J. (2015). Matematické modely pro manažerské rozhodování. Vysoká škola chemicko-technologická v Praze.

Gu, J., Goetschalckx, M., \& McGinnis, L. F. (2007). Research on warehouse operation: A comprehensive review. European Journal of Operational Research, 177(1), 1-21. https://doi.org/10.1016/j.ejor.2006.02.025

Gue, K. R., \& Meller, R. D. (2009). Aisle configurations for unit-load warehouses. IIE Transactions, 41(3), 171-182. https://doi.org/10.1080/07408170802112726

Helo, P. (2000). Dynamic modelling of surge effect and capacity limitation in supply chains. International Journal of Production Research, 38, 4521-4533. https://doi.org/10.1080/00207540050205271

Ho, Y.-C., \& Lin, J.-W. (2017). Improving order-picking performance by converting a sequential zone-picking line into a zonepicking network. Computers \& Industrial Engineering, 113, 241-255. https://doi.org/10.1016/i.cie.2017.09.014

Lahmar, M. (2007). Facility Logistics: Approaches and Solutions to Next Generation Challenges. CRC Press.

Law, A. M. (2013). Simulation modeling and analysis. Fifth edition. McGraw-Hill Education.

Li, K., Li, W., Chen, Z., \& Liu, Y. (2018). Computational Intelligence and Intelligent Systems: 9th International Symposium, ISICA 2017, Revised Selected Papers, Part II. Springer. https://doi.org/10.1007/978-981-13-1651-7

Manzini, R., Ferrari, E., Gamberi, M., Persona, A., \& Regattieri, A. (2005). Simulation performance in the optimisation of the supply chain. Journal of Manufacturing Technology Management, 16, 127-144. https://doi.org/10.1108/17410380510576796 
Manzini, R., Gamberi, M., Persona, A., \& Regattieri, A. (2007). Design of a class based storage picker to product order picking system. The International Journal of Advanced Manufacturing Technology, 32(7), 811-821. https://doi.org/10.1007/s00170-005-0377-2

Önüt, S., Tuzkaya, U. R., \& Doğaç, B. (2008). A particle swarm optimization algorithm for the multiple-level warehouse layout design problem. Computers \& Industrial Engineering, 54(4), 783-799. https://doi.org/10.1016/j.cie.2007.10.012

Pan, J. C.-H., Wu, M.-H., \& Chang, W.-L. (2014). A travel time estimation model for a high-level picker-to-part system with class-based storage policies. European Journal of Operational Research, 237(3), 1054-1066. https://doi.org/10.1016/j.ejor.2014.02.037

Parikh, P. J., \& Meller, R. D. (2008). Selecting between batch and zone order picking strategies in a distribution center. Transportation Research Part E: Logistics and Transportation Review, 44(5), 696-719. https://doi.org/10.1016/j.tre.2007.03.002

Petersen, C. G., \& Aase, G. (2004). A comparison of picking, storage, and routing policies in manual order picking. International Journal of Production Economics, 92(1), 11-19. https://doi.org/10.1016/j.ijpe.2003.09.006

Pichery, C. (2014). Sensitivity Analysis. In P. Wexler (Ed.), Encyclopedia of Toxicology (pp. 236-237). Academic Press. https://doi.org/10.1016/B978-0-12-386454-3.00431-0

Riddalls, C. E., Bennett, S., \& Tipi, N. S. (2000). Modelling the dynamics of supply chains. International Journal of Systems Science, 31(8), 969-976. https://doi.org/10.1080/002077200412122

Shah, J. (2009). Supply Chain Management: Text and Cases. Pearson Education India.

Scholz, A., Henn, S., Stuhlmann, M., \& Wäscher, G. (2016). A new mathematical programming formulation for the SinglePicker Routing Problem. European Journal of Operational Research, 253(1), 68-84. https://doi.org/10.1016/j.ejor.2016.02.018

Sooksaksun, N. (2012). Pareto-Based Multi-Objective Optimization for Two-Block Class-Based Storage Warehouse Design Industrial Engineering and Management Systems, 11(4), 331-338. https://doi.org/10.7232/iems.2012.11.4.331

Tompkins, J. A., White, J. A., Bozer, Y. A., \& Tanchoco, J. M. A. (2010). Facilities Planning. John Wiley \& Sons.

Wang, Q.-Z., Chen, J.-M., Tseng, M.-L., Luan, H.-M., \& Ali, M. H. (2020). Modelling green multimodal transport route performance with witness simulation software. Journal of Cleaner Production, 248, 119245. https://doi.org/10.1016/i.jclepro.2019.119245

Yu, M., \& de Koster, R. B. M. (2009). The impact of order batching and picking area zoning on order picking system performance. European Journal of Operational Research, 198(2), 480-490. https://doi.org/10.1016/i.ejor.2008.09.011

Yu, Y., De Koster, R., \& Guo, X. (2015). Class-Based Storage with a Finite Number of Items: Using More Classes is not Always Better. Production and Operations Management, 24, 1235-1247. https://doi.org/10.1111/poms.12334

Editorial record: The article has been peer-reviewed. First submission received on 7 March 2021. Revisions received on 9 April 2021 and 13 May 2021. Accepted for publication on 14 May 2021. The editor in charge of coordinating the peer-review of this manuscript and approving it for publication was Stanislava Mildeova (D).

Acta Informatica Pragensia is published by Prague University of Economics and Business, Czech Republic. 